\title{
Fertility and Family Planning in India and Kenya
}

\author{
RIIKKA RAITIS
}

\author{
Assistant Researcher \\ Research Group for Comparative Sociology \\ University of Helsinki
}

RIITTA SAARINEN

\author{
Postgraduate Student \\ Department of Sociology \\ University of Helsinki
}

\section{Introduction}

This article deals with attitudes towards family planning and the fertility pattern in two culturally and geographically different societies in developing countries: in a fast growing slum area in Calcutta, India and in an agricultural area under great population pressure in Kenya ${ }^{1}$.

The aim of the article is to compare attitudes and ideas about family planning and the factors affecting family planning in the two localities as well as estimate what changes in fertility the current trends in family planning will entail.

\section{The Calcutta project}

The subject area in the Calcutta project was three squatter settlements - wild areas, illegal slums - in the Salt Lake area of Calcutta. Calcutta, the capital of WestBengal, has a population of about 12 million inhabitants, which makes it the largest city in India. The number of squatters is growing rapidly. In 198132 percent of the

\footnotetext{
1 The article is based on Riitta Saarinen's master's thesis "How God's gift turned out to be an economic burden - Family planning in three squatter settlements of Calcutta» at the Department of Sociology, University of Helsinki and Riikka Raitis' »Population growth and fertility in Kenya and a case study of the Taita-Taveta District» at the Department of Geography, University of Helsinki. Riitta Saarinen's study is part of a research project which was carried out at the Department of Sociology. The project was financed by the Ministry of Education. Riikka Raitis participated in a project arranged by the Department of Geography and sponsored mainly by The Finnish Agency for Development Co-operation (FINNIDA). This article could be considered part of the newly introduced activity of Väestöliitto, the Finnish Population and Family Welfare Federation, that of consultant in population development aid.
} 
Calcuttans lived in slums, in 1990 the percentage of slum dwellers was estimated to have reached 44 percent.

The basic information was gathered with a survey of about one hundred households. The survey included about 60 questions dealing with family structure, the family's economic situation, work history, education, religion, political activity, health, family planning, etc. After the survey had been carried out, six 18-35-year-old women were chosen for in-depth interviews. Special emphasis was laid upon the use of contraception in practice. The women's knowledge, attitudes and practice of contraception were carefully mapped out (as in the Indian KAP-studies). All the interviewees were married and four of them worked outside the home.

The in-depth interviews included questions on the women's attitudes toward family planning, how many children they wanted and how they actually practiced family planning and if they had any problems with contraception.

The interest was focused on family planning with modern contraception as well as with traditional methods, the women's opinions on different methods of contraception, the advantages and disadvantages of the methods, reasons for wanting a child, the relationship between fertility and socio-cultural factors and rationales behind the fertility behavior.

Further information on family planning in Calcutta was obtained by visiting the governmental offices of West-Bengal and the most important voluntary organizations. Also, local family planning clinics were visited.

Economic fertility theories were applied but seemed to be too simplified to explain as delicate a subject as fertility behavior.

\section{The Kenya project}

The main part of the Kenya project was conducted in the Taita-Taveta District, which is located in the southeastern part of Kenya, near the border of Tanzania. In 1988 it was estimated that about 209,000 inhabitants lived in the Taita-Taveta district. Interviews were made in two villages, Werugha and Dembwa.

The fieldwork involved collecting information from the visitor registers of two family planning clinics, six interviews with family planning workers, and 14 interviews concerning people's attitudes towards (and experience of) children, fertility control and child mortality. Data from the population censuses made in Kenya in 1969 and 1979 and the Kenya Contraceptive Prevalence Survey in 1984 were also used.

The theoretical framework was based on Easterlin's theory on demand for children, supply of children and cost of fertility control, and on Bongaarts' approach concerning proximate determinants of fertility.

According to these theories, family size preferences and child costs determine the demand for children. The level of natural fertility and child mortality determine the supply of children. The greater the excess of supply over demand, the greater is the motivation for fertility control. If the motivation results in fertility control, this means the beginning of the fertility transition. (Easterlin and Crimmins 1985, 14-18).

Most of the variation in the fertility level in Kenya is explained by the marriage pattern, post-partum infecundability (delay in the return of ovulation caused by breastfeeding) and the use of contraceptives (proximate determinants). The demand for children represented by ideal family size and the supply of children represented by child mortality affect the motivation for fertility control (motivation determinants). Both groups of determinants are affected by socio-economic and cultural factors. (Bongaarts and Potter 1983, 78-79; Cochrane and Farid 1989, 28.) 
Figure 1. The theoretical framework of the study.

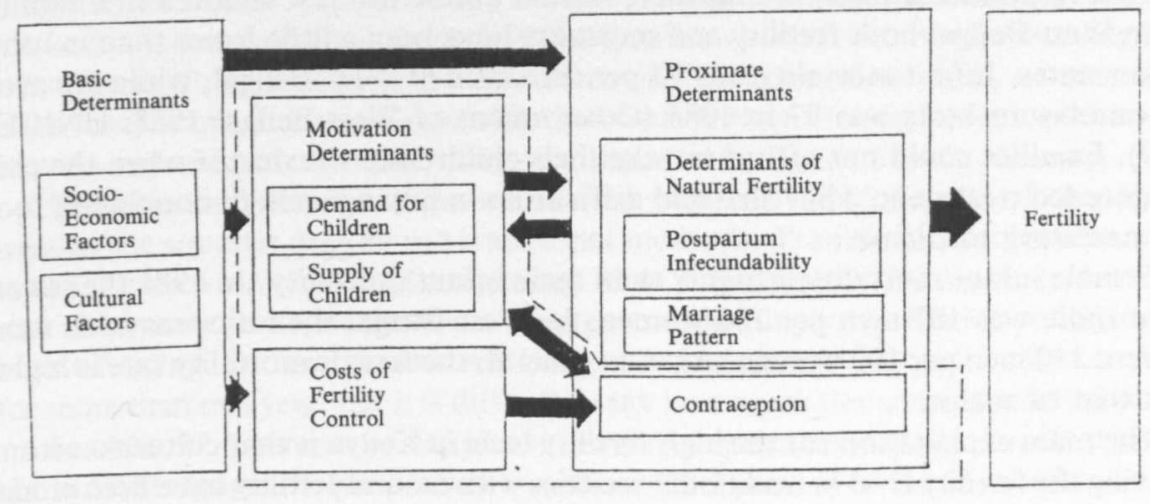

Socio-economic factors, like education level and urbanization, and traditional fertility-related norms and customs affect fertility through proximate determinants, the ideal number of children and infant and child mortality.

Figure 1 shows the framework used. The factors within the broken line are those which have received extra emphasis during the fieldwork.

\section{Recent fertility trends in the localities studied}

Family planning has a long tradition in India and Kenya. In India, the first family planning clinic started as early as 1925 . The first voluntary association, the Family Planning Association of India, was started in 1949 and the first family planning program in the world in 1952.

In Kenya, government activities for family planning started early compared with the rest of sub-Saharan Africa. The Family Planning Association of Kenya was established in the early 60 s by a group of private Kenyan individuals. Concern about the rate of population growth was noted in a Government Statement of Kenya's National Goals in 1965 and the national family planning program officially began in 1967 .

Despite a rather long tradition of population policy, including family planning, the fertility level has remained high in Kenya, and even increased in the past few years. The desired number of children is high, and though infant and child mortality have decreased, they may still be factors increasing desired fertility.

In India the total fertility rate was 4.2 in 1987 . People living in the squatter settlements of Calcutta wanted to have two or three children and also actually had on average of 2.5 children per family.

In Kenya, the total fertility rate was on average of 7.7 in 1984 (RoK 1984, 52). In the Taita-Taveta District it has been below the national average, but has now increased to about the same level.

The fieldwork seems to point out that the high fertility pattern may now be changing. Marked changes have occurred between the time of the Kenya Contraceptive Prevalence Survey made in 1984 and the fieldwork made in 1989.

Infant mortality was relatively high. In Kenya infant mortality was 73 per thousand in 1987, but 85 per thousand in the in the Taita-Taveta District (RoK N.D., 
34; UNICEF 1989, 102). The possible death of a child is still an important reason why the respondents thought that there should not be too few children in a family.

In West-Bengal both fertility and mortality have been a little lower than in other Indian states. Infant mortality was 74 per thousand in West-Bengal, while the average number in India was 97 in 1985 (Government of West-Bengal 1988; UNICEF 1989). Families could not afford to take their children to the doctor when the children needed treatment. They also had difficulties in buying enough nourishing food and necessary medicine.

Female infant mortality is higher than male infant mortality. In 1981 the sex ratio in India was 107 men per 100 women. In West-Bengal the ratio was even more uneven: 110 men per 100 women. Also, in general, the female mortality rate is higher than that of males.

The main explanation for the high fertility level in Kenya is that cultural customs reducing the fertility level in traditional societies with natural fertility have been eroded by the socio-economic changes in society, without any significant replacement of individually-used fertility control methods. In the traditional society, extended breastfeeding was the most important method. However, this and other birth-spacing customs were aimed at decreasing the child mortality level, not fertility.

The interviews done in the Taita-Taveta District and in the squatter settlements of Calcutta showed that motivation for family planning was high.

The motivation for fertility control in Kenya is high for several reasons. The cost of fertility control is low because of the declining social pressure against fertility control, a generally positive attitude towards fertility control and an improved access to knowledge and methods. The social pressure has been declining because the decisions about fertility control are more and more thought to concern only the husband and wife, even if the pressure of relatives towards larger families still exists.

The ideal number of children has decreased in India as well as in Kenya. In Calcutta the ideal and real number of children were the same.

In Taita-Taveta the ideal number of children had decreased from six in 1984 to four in 1989, and this number is usually lower than the actual number in the family. According to the interviews the ideal number of children in the family was four, although the real family size (average 5.5) often exceeded the ideal size.

In Calcutta people seemed to know about family planning and definitely wanted to have a small family. None of the interviewees wanted to have more than two or three children. In reality, they also had small families: On an average, there were 2.5 children in the family.

In Kenya 15.0 percent of women in fertile age used some modern or traditional methods of family planning in 1984 , and 11.3 percent of women used modern or traditional methods of contraception in 1984 in the Taita-Taveta District. (RoK 1984, 84; RoK 1986, 110.)

The records of two family planning clinics in Taita-Taveta showed that women usually start to use contraceptives in their twenties. Injection has become the most common method, the second most common being the pill. According to family planning workers, the lack of resources and prejudices against contraceptives are reducing the proportion of women using contraceptives.

The biggest problem of family planning in Calcutta seemed to lie not in knowledge or attitudes but in the many risks and side effects the methods of contraception have. Poor people who belong to lower classes and castes have to make their decicions concerning family planning and health care according to their economic situation. They cannot afford private health services or expensive medicine and much needs to be improved in the services of communal health centers and hospitals. 
The women interviewed in Calcutta as well as their husbands weighed family planning in their minds very carefully, comparing the risks and the advantages. All the methods used nowadays - including sterilization - seem to have disadvantages and side effects. People had many difficulties with contraception. Also, after-care was often insufficient. It is understandable that many women are suspicious and also afraid to take any measures, even if they are eager to carry out family planning.

The risks and disadvantages of modern methods induced most of the interviewees in the squatter area to use traditional methods. Traditional methods were used especially between children for spacing. Most important of the traditional methods was abstinence in its many forms. Postpartum abstinence is often strengthened by breast-feeding. In the squatter settlements women breastfed their children usually for more than one year, but it is difficult to say how much this actually affected fertility.

In India 37.5 percent of couples in fertile age practiced family planning in 1987 , but in West-Bengal the proportion was lower: 30.1 percent of fertile couples (Government of West-Bengal 1988; India 1989, 105).

When parents finally thought that they had enough children, most women chose sterilization. However, sterilization was performed only after the desired number of children had been reached. Abortion was not very common and women seemed to have an ambivalent attitude towards it. Neither was the IUD very popular because many were afraid of its side effects. According to the reports of the Family Planning Association of India (Calcutta Project), 84 percent of those starting family planning chose sterilization. After that came the IUD, the pill and the condom. In the squatter settlements the condom was not popular and injection almost totally unknown, but the interest in pills was clearly increasing, especially in the younger age groups. The women interviewed were not interested in their husbands having vasectomies. Many people had bad memories about the time of the Emergency and Mass Vasectomy Camps and thus rejected male sterilization. Women also calculated and compared the risks of the operation. Many of the interviewees were afraid that the whole family would be in big trouble if the husband, the breadwinner of the family, got ill after the operation. Because medicine is very expensive, many of those interviewed were deeply worried about someone in the family getting ill.

\section{A Comparison of the effect of socio-cultural factors}

Social, cultural and economic factors influence family planning directly or indirectly. Social circumstances are strongly connected with the role of women and economic independence, work outside the home and the right to control property.

One of the most important socio-cultural factors influencing family planning in India is the status of the Indian woman and her roles as wife and mother. Social status can not be determined unambiguously, because it differs from individual to individual depending on religion, caste, age, position, education etc. It is often difficult to separate the effects of these various factors because of their interaction. Other important social-cultural factors are religion, education and working outside the home.

Children meant benefits as well as expenses for their parents. The interviewees often emphasized that economic points of view have to be taken into consideration in family planning. Old-age security was the most important reason people gave for having children. Parents expected old-age security from their sons, not from the daughters, who move away from home after marriage. Indian parents also have to invest in their children in order to give them an education, and to pay the dowries for their daughters. 
It is difficult to make direct comparisons about the effects of sociocultural factors on fertility and family planning in India and Kenya. The life of the Kenian and Indian woman differs in many respects. However, one of the main differences is the stronger preference for a son in India than in Kenya. There are many socio-cultural and economical factors, which effect the preference for a son (India 1988, 24; Women and Population Dynamics 1989,227 .) The fact that in India the parents of a bride are expected to provide their daughter with a dowry for the bridegroom in order to get their daughter married is one important reason. Paying dowries can cause difficult economic problems in families, especially when there are many daughters and no sons. In Kenya there is bridewealth instead of a dowry. The bridegroom gives cows or money to the parents of his bride.

Generally, education is considered the single most important factor affecting the status of women and thus efficiently reducing fertility. Fertility rates generally decrease when length of schooling increases. However change will be seen clearly only after the woman has passed high school or studied further. The effect of women's education on fertility is curvilinear in Kenya. Women with $1-4$ years of education have a higher fertility level than those with no education. Basic education improves hygiene and health care and shortens the duration of breast-feeding. (RoK 1984, 52; Uitto 1989,101 .)

Results have been similar in some studies made in India. In Calcutta it could not be seen that education, as such, would have effected the use of contraception. Most women respondents who had attended school had studied for a few years. Among women one-half could read and among men two out of three. Education and fertility are connected with each other through various social, economic and psychological processes and consequences. Formal education, as such, does not necessarily affect fertility, but is often connected with the urban way of life and economic development, which make it easier to adopt new ideas. In cities health services are found nearby and it is more common for women to work outside the home. (Agarwala 1977, 48; Chatterjee 1979, 34; Chaudhury 1982, 84; Mandelbaum 1974, 51-59; RoK 1984, 49; RoK 1986, 39; Safilios-Rotchild and Mburugu 1986, 9-11).

In neither Taita-Taveta nor in Calcutta does fertility correlate with the woman's employment outside the home. If a woman's status is primarily based on the traditional mother/wife role and her economic role remains marginal and unimportant, the number of children does not decrease only by working »outside the home». It is also difficult, both in Kenya and in India, to get statistics about working women, because the definition of work is unclear, and most work is done at home. More than 80 percent of the women in Taita-Taveta District reported that they have "never worked", and no marked differences could be seen in fertility between working women and women at home. In Calcutta 40 percent of squatter women worked outside the home, but there was no correlation between employment and fertility. Heavy, dull and poorly paid work outside the home did not mean a career for these women but an economic necessity. (Chahil 1977, 163; RoK 1986, 39; Women and Population Dynamics 1989, 192-194.)

Religion was also a factor which did not seem to have any significant effect on fertility in the studies, be it in Taita-Taveta or Calcutta. In Calcutta most of the interviewees did not associate family planning with religion in any way. Even though children were thought to be gifts from God, family planning was considered absolutely necessary. There was no difference between the fertility of Hindus and Muslims, but Muslims represented a minority among the respondents.

Early and universal marriage increases fertility in both countries. Kenyan women 
as well as Indian women are on average, slightly over 18 years old at the time of their first marriage.

In Kenya close to 80 percent of women are married before they reach 25 years of age. The mean age at marriage was 18 in the Taita-Taveta District. Almost every woman is married before the age of 20 . Age at marriage rises uniformly with education. 25 percent of Kenyan women lived in a polygamous union in 1984, but the percentage is declining. Some reports show that women living in polygamous unions have a lower fertility on average than those living in monogamous unions. (Cochrane and Farid 1989, 51-53, 107-108; Ochola-Ayayo 1988, 57; RoK 1984, 39-43.)

In the squatter settlements of Calcutta women seemed to get married earlier than women belonging to higher social classes. Most interviewed squatter women had been married between the age of 15 and 19 years. The average age of marriage was 15 , but the age had clearly risen so that in younger age groups most women got married when they were 18 to 19 . Education and literacy seem to be the most important factors affecting the woman's age at marriage in India.

\section{Main findings and conclusions}

A high fertility level was rational in the traditional society. It was needed for compensating high mortality, and it was useful both at the nuclear family and extended family level, where children formed an important source of labor force and old age support. Therefore traditional values are against birth control. Modernization and forming nuclear families increase child costs and decrease the utility received from children. This usually results in smaller ideal family size and higher motivation for family planning. In India this motivation has already resulted in an increase of the use of contraceptives and in a declining fertility rate. In Kenya the fertility rate has been rising for a long time, but it now seems that the use of contraceptives is going to increase to a level where the fertility transition can begin.

The fertility level is higher in rural than in urban areas. Contraceptive use reduces fertility in major urban areas and among the most educated women. Education also raises age upon first marriage, eliminates very large desired family sizes and reduces infant and child mortality. However, it also leads to a decline in what is traditionally the most important fertility-reducing factor, breast-feeding. The most important factor reducing fertility below its biological maximum in Kenya is breast-feeding, whereas early, universal marriage and little use of effective contraceptives keeps fertility levels high. (Cochrane and Farid 1989, 73, 82; Uitto 1989, 98-101).

Fertility differs among the ethnic groups, but religion does not have any pronounced impact. Traditional norms are usually against individual fertility control, i.e. use of contraceptives, and thus increase the psychic costs of fertility control. However, traditional customs, like long breast-feeding and abstinence after delivery, decrease the fertility level (Cochrane \& Farid 1989, 45, 69; RoK 1984, 46-52).

Even though these two studies have been carried out in culturally and geographically different surroundings, there were many similarities between the attitudes and ideas of the respondents on Taita-Taveta and Calcutta. Changes in fertility behavior seem to be heading in the same direction in Kenya and India.

The demand for children has been very high in Kenya and rather high in India, too. The supply of children has risen in Kenya till recently, partly due to the increased fertility level, possibly caused by shortened duration of breast-feeding (even if it still is long) and increased fecundability, and partly due to the decreased level of child mortality. 
Since the use of contraceptives has been low in Kenya, the largest part of the difference between biological maximum level of fertility and the actual level of fertility has been caused by the ovulation-delaying effect of breast-feeding. Now the situation seems slowly to be changing. Family planning is becoming a more important fertility-reducing factor in Kenya than before, and thus the situation now is reminiscent more and more of India.

\section{References}

Agarwala, S.N. (1977). Population. New Delhi: National Book Trust of India.

Bongaarts, John and Potter Robert G. (1983). Fertility, Biology and Behavior: an Analysis of the Proximate Determinants. Studies in Population. New York: Academic Press.

Chahil, Renu (1977). The status of women, work and fertility in India. In: The Fertility of Working Women, edited by Stanley Kupinsky. New York: Presker Publishers.

Chatterjee, Pranab Kumar (1979). Aspects of Human Fertility: a Socio-Economic Study. Kalyani: University of Kalyani.

Chaudhury, Rafiqul Huada and Latif, A. (1982). Social Aspects of Fertility with Special Reference to Developing Countries. New Delhi: Vilkas Publishing House.

Cochrane, Susan H. and Farid, Samir M. (1989). Fertility in Sub-Saharan Africa. World Bank Discussion Papers 43. Washington DC: The World Bank.

Easterlin, Richard A. and Crimmins, Eileen M. (1985). The Fertility Revolution: a Supply-Demand Analysis. Chicago: The University of Chicago Press.

Government of West-Bengal State Family Welfare Bureau (1988). Report on Progress of Family Welfare Programme.

India 1989. Annual Review (1989). Competition Review, edited by S.K. Sachdeva. New Delhi.

Mandelbaum, D.G. (1974). Human Fertility in India: Social Components and Policy Perspective. Berkeley: University of California Press.

Ocholla-Ayayo, A.B.C. (1988). Cultural codes and population change in Kenya. In: Kenya's Population Growth and Development to the Year 2000, edited by by S.H. Ominde pp. 57-65. Nairobi: Heinemann Kenya.

RoK (Republic of Kenya) (1981). Population Cencus 1979. Volume I. Kenya: Central Bureau of Statistics, Ministry of Economic Planning and Development.

RoK (1984). Kenya Contraceptive Prevalence Survey 1984. First Report. Nairobi: Central Bureau of Statistics, Ministry of Planning and Development.

RoK (1986). Kenya Contraceptive Prevalence Survey 1984. Pronvincial Report. Nairobi: Central Bureau of Statistics, Ministry of Planning and National Development.

RoK (N.D.). Taita Taveta District Development Plan 1989-1993. Kenya: Ministry of Planning and National Development.

Safilios-Rotchild, Constantina and Mburugu, Edward K. (1986). Women's Income and Fertility in Rural Kenya. Working Paper 441. Nairobi: Institute for Development Studies, University of Nairobi.

Uitto, Juha (1989). The Kenyan Conundrum. Meddelanden från Lunds Universitets Geografiska institutioner, avhandlingar 107. Uppsala: Lund University Press.

UNICEF (1990). The State of the World's Children 1989. Oxford: Oxford University Press.

United Nations (1988). 1986 Demographic Yearbook. New York: Department of International Economic and Social Affairs, Statistical Office.

Women and Population Dynamics: Perspectives from Asian Countries, edited by K. Mahadevan. (1989), New Delhi: Sage Publications. 


\section{Abstract}

This article compares the fertility pattern and the attitudes towards family planning in two culturally and geographically different societies, the growing slum area in Calcutta, India and Taita-Taveta, an agricultural area under high population pressure in Kenya. The studies are partly demographic and partly based on in-depth interviews. 